\title{
Eksplorasi Tana Toraja Dalam Media Game Digital Genre Puzzle
}

\author{
Diajeng Fitri Aulia Niza ${ }^{1}$, \\ Samuel Gandang Gunanto ${ }^{2}$, Andri Nur Patrio ${ }^{3}$ \\ Program Studi Animasi, ISI Yogyakarta \\ Email: diajengfitriaulia@gmail.com¹,gandang6@gmail.com², \\ andrinurpatrio@gmail.com ${ }^{3}$
}

Abstrak

Game "Lost in Toraja" merupakan game edukasi 2D yang ber-genre adventure puzzle. Game ini memiliki karakter bernama Orion yang akan mengeksplorasi sebuah tempat di Indonesia, yaitu Tana Toraja di Sulawesi Selatan. Orion merupakan karakter yang berasal dari Jawa Barat. Kedatangannya ke Tana Toraja adalah untuk mencari adiknya yang menghilang secara misterius ketika sedang berlibur.

"Lost in Toraja" memiliki playtime sekitar 30-45 menit. Pemain akan berperan sebagai karakter yang akan memasuki sebuah area permainan, lalu diminta untuk mencari jalan keluar. Pemain juga akan ditantang kecerdasannya dalam memecahkan puzzle yang ada di setiap level. Pembuatan game ini menggunakan teknik digital dan game engine Unity, ditujukan untuk pengguna mobile phone dengan platform android.

Game ini dibuat dengan tujuan untuk mengenalkan budaya dan legenda turuntemurun yang ada di Tana Toraja pada rakyat Indonesia maupun internasional. Dengan media yang menyenangkan, pemain akan diajak untuk bermain sekaligus belajar.

Kata kunci: Game, Adventure-Puzzle, 2D, Education, Tana Toraja.

\begin{abstract}
Lost in Toraja game is an educational game with adventure-puzzle genre. The main character is Orion, who explores Tana Toraja, South Celebes, one of local area in Indonesia. Orion is a character from West Java, and his intention to Tana Toraja is looking for her missing sister when she's on her trip there.

Lost in Toraja has a playtime around 30-45 minutes. The player will become a main character, who enter the game area, and they have to find the way out. Each area has several puzzle that player has to solved. The game was made using digital technique in Unity game engine, and will be build in Android platform and Windows platform.

The game's intention is to spread Tana Toraja culture among Indonesian's citizen itself, even into foreign country. Game is a pleasing media to have fun and leart at once.
\end{abstract}

Keywords: Game, Adventure-Puzzle, 2D, Education, Tana Toraja. 


\section{PENDAHULUAN}

\section{Latar Belakang}

Perkembangan teknologi telah berkembang sangat pesat dalam satu dekade terakhir. Seiring perubahan zaman dan teknologi, perkembangan industri game di dunia ternyata menciptakan potensi bisnis dengan nilai yang cukup luar biasa, termasuk di Indonesia.

Unity Technology, salah satu pengembang aplikasi pembuatan game merilis laporan yang menyatakan bahwa pemasukan industri game mobile global telah mencapai US\$40,6 miliar atau sekitar Rp 547 trilyun. Berdasarkan data tersebut, angka pemasangan aplikasi game di Indonesia tiga kali lebih tinggi dibanding di US, Meksiko, dan India (Risky Maulana, "Tingkat Perkembangan Pasar Game Mobile Tiga Kali Lipat dari Amerika Serikat”, diakses dari http://id.techinasia.com/perkembangan-pasar-game-indonesiasalah-satu-yang-tertinggi-di-2016, pada tanggal 11 Desember 2017 pukul 08.15)

Selain untuk media hiburan, game dapat digunakan sebagai media pembelajaran yang mengedukasi masyarakat. Pemain akan menyerap informasi yang disampaikan oleh developer dengan pendekatan bermain sambil belajar, sehingga memudahkan penyampaian ilmu dan pengetahuan.

Maraknya konten game yang mengandung unsur kekerasan telah menjadi tren yang tak bisa dihindari pada saat ini. Kemudahan teknologi membuat remaja tanggung bahkan anak-anak dengan mudah mengakses permainan apa saja, termasuk yang mengandung konten kekerasan

Mengingat rawannya dampak game berkonten kekerasan terhadap remaja, penulis berinisiatif menciptakan game yang memiliki konten netral, maupun edukatif.

\section{Rumusan Masalah}

Berdasarkan latar belakang yang telah dikemukakan, dapat dirumuskan permasalahan sebagai berikut :

- Game secara tidak langsung merupakan media penyampaian informasi, kualitas konten game akan mempengaruhi apa yang akan diterima oleh player secara psikologi.

- Maraknya game yang lebih cenderung ke genre action dengan banyaknya adegan kekerasan. 


\section{Tujuan}

Tujuan penulisan makalah ini adalah :

- Membuat game puzzle-adventure

- Membuat game edukasi yang menyenangkan namun melatih kecerdasan otak.

- Game ini memakai bahasa pengantar Bahasa Inggris, sehingga diharapkan pemain internasional dapat mengenal budaya Indonesia.

\section{Target Audien}

Target audien dari game adalah ;

$$
\begin{array}{ll}
\text { Usia } & : \text { 14 tahun keatas } \\
\text { Jenis kelamin } & \text { : Laki-laki dan perempuan } \\
\text { Pendidikan } & \text { : Dari latar pendidikan apapun } \\
\text { Status sosial } & \text { : Semua kalangan }
\end{array}
$$

\section{Indikator Capaian Akhir}

Indikator yang dicapai dalam pembuatan game "Lost in Toraja" dibagi menjari tiga tahapan, yaitu praproduksi, produksi, dan pascaproduksi.

\section{LANDASAN TEORI}

\section{Game}

Menurut KBBI, permainan adalah sesuatu yang digunakan untuk bermain, barang atau sesuatu yang dipermainkan. Permainan adalah bentuk aktivitas yang menyenangkan yang dilakukan semata-mata untuk aktivitas itu sendiri, bukan karena ingin memperoleh sesuatu yang dihasilkan dari aktivitas tersebut. (Desmita, Psikologi perkembangan, 2005)

Permainan (games) adalah setiap kontes antara pemain yang berinteraksi satu sama lain dengan mengikuti aturan-aturan tertentu untuk mencapai tujuan tertentu pula (Sadiman, 1993:75).

\section{Video Game}

Asal usul permainan video/video game terletak pada awal tabung sinar katoda berbasis pertahanan peluru kendali sistem pada akhir 1940-an. Program-program ini kemudian diadaptasi ke dalam permainan sederhana lainnya di era tahun 1950-an.

Sistem elektronik yang digunakan untuk menjalankan permainan video disebut platform. Contohnya adalah komputer pribadi dan konsol permainan. Bahkan ada 
beberapa perangkat yang diciptakan secara eksklusif hanya untuk bermain video games, seperti Playstation, Xbox One, Nintendo Switch, dll.

\section{Game Edukasi}

Educational game atau permainan edukasi adalah game digital yang dirancang untuk pengayaan pendidikan atau mendukung pengajaran dan pembelajaran, menggunakan teknologi media interaktif (Ritzhaupt, A., Higgins, H. \& Allred, B,2010).

Suka bermain adalah sifat alami manusia sesuai dengan usia individu. Disamping sebagai hiburan, keberadaan game edukatif akan menjadi metode pembelajaran dengan cara yang menyenangkan.

\section{Skizofrenia}

Skizofrenia merupakan penyakit mental yang serius. Penyakit ini disebabkan oleh gangguan konsentrasi neurotransmiter otak, dan perubahan reseptor sel-sel otak. Gejalanya adalah mengalami delusi, yakni memiliki keyakinan yang kuat terhadap suatu hal tanpa dasar yang jelas, tetap teguh walaupun bukti menyatakan sebaliknya dan tidak bisa dikoreksi dengan akal sehat. Pasien juga dapat mengalami halusinasi, seperti merasakan sesuatu yang sangat nyata, yang sebenarnya tidak ada.

\section{Edukasi Tana Toraja}

Indonesia memiliki banyak sekali budaya dalam masing-masing sukunya. Salah satu etnis yang diusung dalam game "Lost in Toraja" adalah Tana Toraja, kelompok pribumi di daerah pegunungan Sulawesi Selatan, Indonesia.

Dalam masyarakat Tana Toraja, ritual pemakaman adalah acara yang paling sakral dan mahal. Yang kaya dan lebih kuat individunya, akan mendapatkan pemakaman yang mahal. Kematian pesta bangsawan biasanya dihadiri oleh ribuan dan berlangsung selama beberapa hari.

Sebuah situs upacara, yang disebut rante, biasanya dibuat dalam besar, lapangan rumput di mana tempat penampungan untuk pengunjung, lumbung, dan struktur pemakaman seremonial lainnya khusus dibuat oleh keluarga almarhum. Musik seruling, nyanyian pemakaman, lagu dan puisi, dan menangis dan meratap adalah ekspresi tradisional Toraja. 


\section{PERANCANGAN}

1. Deskripsi Game

\begin{tabular}{|c|c|}
\hline Abstraksi & $\begin{array}{l}\text { : Pemain memainkan karakter utama yang mencari } \\
\text { keberadaan adiknya, yang menghilang saat berlibur ke } \\
\text { Tana Toraja. }\end{array}$ \\
\hline Genre & : Adventure-Puzzle-Psychology \\
\hline Theme & : Mystery \\
\hline Visual Style & $: 2 \mathrm{D}$ \\
\hline Player & : Single Player \\
\hline \multicolumn{2}{|c|}{ Player Immersion: Adventure, Story } \\
\hline \multicolumn{2}{|c|}{ Consumer Group : Everyone } \\
\hline Playtime & : 30-45 menit \\
\hline
\end{tabular}

2. Konsep Game

Konsep dari game "Lost in Toraja” bermula dari edukasi mengenai budaya lokal Indonesia.

Game "Lost in Toraja” memiliki tiga unsur, yakni edukasi, petualangan, dan cerita fiktif. Sambil berpetualang menjelajahi beberapa lokasi di Toraja, pemain akan disuguhkan cerita fiktif mengenai karakter Orion, yang menemukan banyak informasi budaya seiring penjelajahannya di Tana Toraja.

\section{Sinopsis}

Orion berusaha mencari tahu keberadaan adiknya, Vega, yang telah menghilang selama 3 hari di Tana Toraja. Ia menceritakan perihal Vega kepada salah seorang kawannya, bernama Nanda. Mendengar cerita Orion, Nanda pun menyuruh Orion menyusul ke Tana Toraja.

Di Tana Toraja, Orion mencari adiknya. Pencariannya berakhir di Air Terjun Sarambu, dimana dia akhirnya menemukan Vega. Namun Vega yang ia temukan adalah halusinasinya semata, karena mengalami trauma akan kematian Vega di Air Terjun Sarambu ini, 3 bulan yang lalu. 
Nanda yang menyuruh Orion ke Tana Toraja, juga merupakan delusi yang dihasilkan pikirannya. Nanda mengingatkan Orion bahwa Vega sudah meninggal, namun delusinya menangkap bahwa Nanda menyuruhnya menyusul Vega ke Tana Toraja.

Sehari setelah percakapan tersebut, Nanda mengetahui bahwa Orion sudah ada di Toraja, dan menyusulnya. Ia pun berhasil membawa Orion pulang.

4. Sistem Mekanika Permainan

Pemain akan berperan sebagai Orion, yang akan menjelajahi area permainan di Tana Toraja.

Tujuan dari penjelajahan adalah mencari saudara kembarnya, Vega yang menghilang saat berlibur di Tana Toraja. Orion akan memasuki area permainan dan harus mencari jalan keluar sambil menghindari rintangan dan mencari beberapa item yang dibutuhkan untuk menemukan Vega.

Beberapa mekanika utama gameplay dalam "Lost in Toraja” dijabarkan sebagai berikut :

1) Karakter dapat bergerak 4 arah, atas, bawah, kanan, dan kiri.

2) Karakter dapat menyerang dengan senjata yang telah diberikan

3) Karakter harus menghindari musuh dan jebakan

4) Karakter akan mendapatkan beberapa item yang berhubungan dengan alur cerita

5) Terdapat beberapa 4 chapter cerita pendukung di dalam game.

Terdapat tiga lokasi yang dapat dimainkan pemain, masing-masing lokasi memiliki tiga level. Cerita pada game akan dibagi menjadi 4 bagian, prolog, 2 chapter cerita, dan epilog. Cerita-cerita ini akan disisipkan diantara tiap level. 


\section{Desain Karakter}

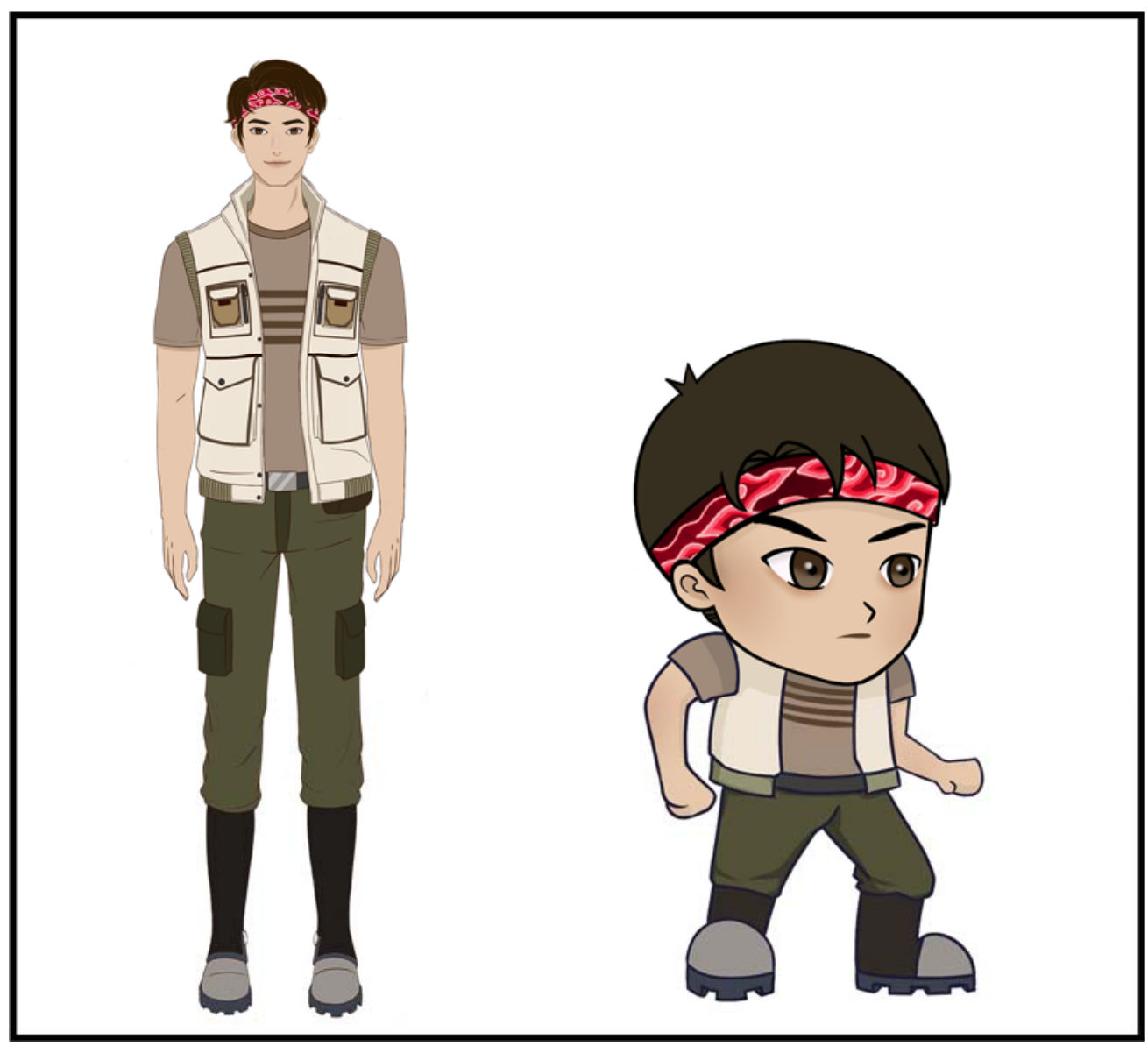

Gambar 1. Desain karakter Orion, dalam cerita (kiri), dan dalam game (kanan)

Karakter utama game ini, yang akan menjelajahi seluruh area permainan. Orion adalah kakak laki-laki Vega. Orion memiliki jurnal khusus untuk mendokumentasikan lokasi-lokasi yang dikunjungi. Isi jurnal Orion adalah sketsa-sketsa ciri khas lokasi atau budaya yang bersangkutan, dan ditambahi informasi mengenainya.

Gangguan skizofrenia Orion mulai muncul pada saat kematian Vega. Ia sulit menerima hal tersebut, sehingga memicu halusinasi dan beranggapan bahwa Vega masih hidup. 
6. Desain Level Permainan

Game "Lost in Toraja" merupakan permainan yang berbentuk platform, memiliki 9 desain level yang berbeda-beda. Salah satu contoh desain levelnya, dapat dilihat pada gambar berikut :

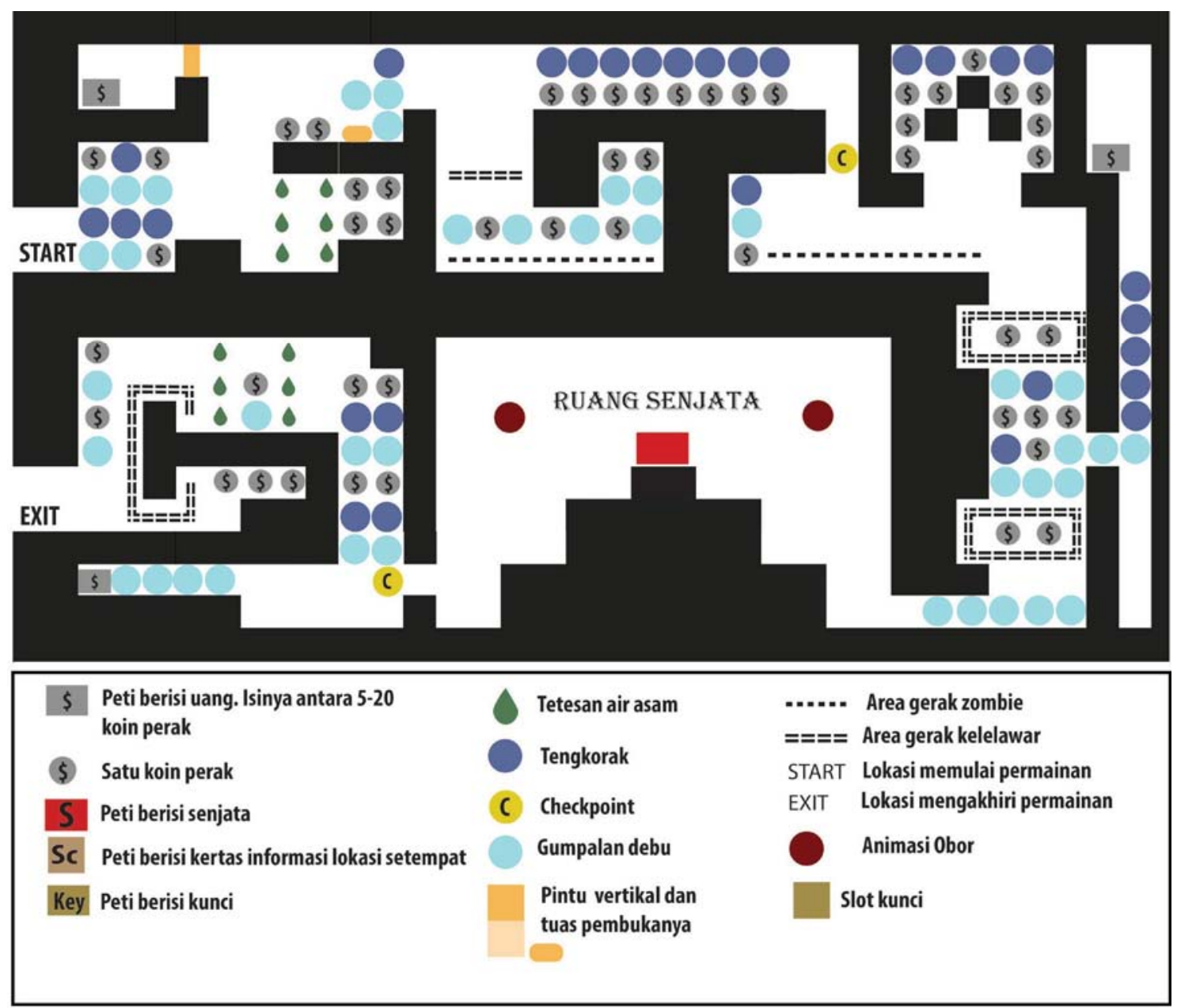

Gambar 2. Desain Level Permainan 


\section{Desain gameplay}

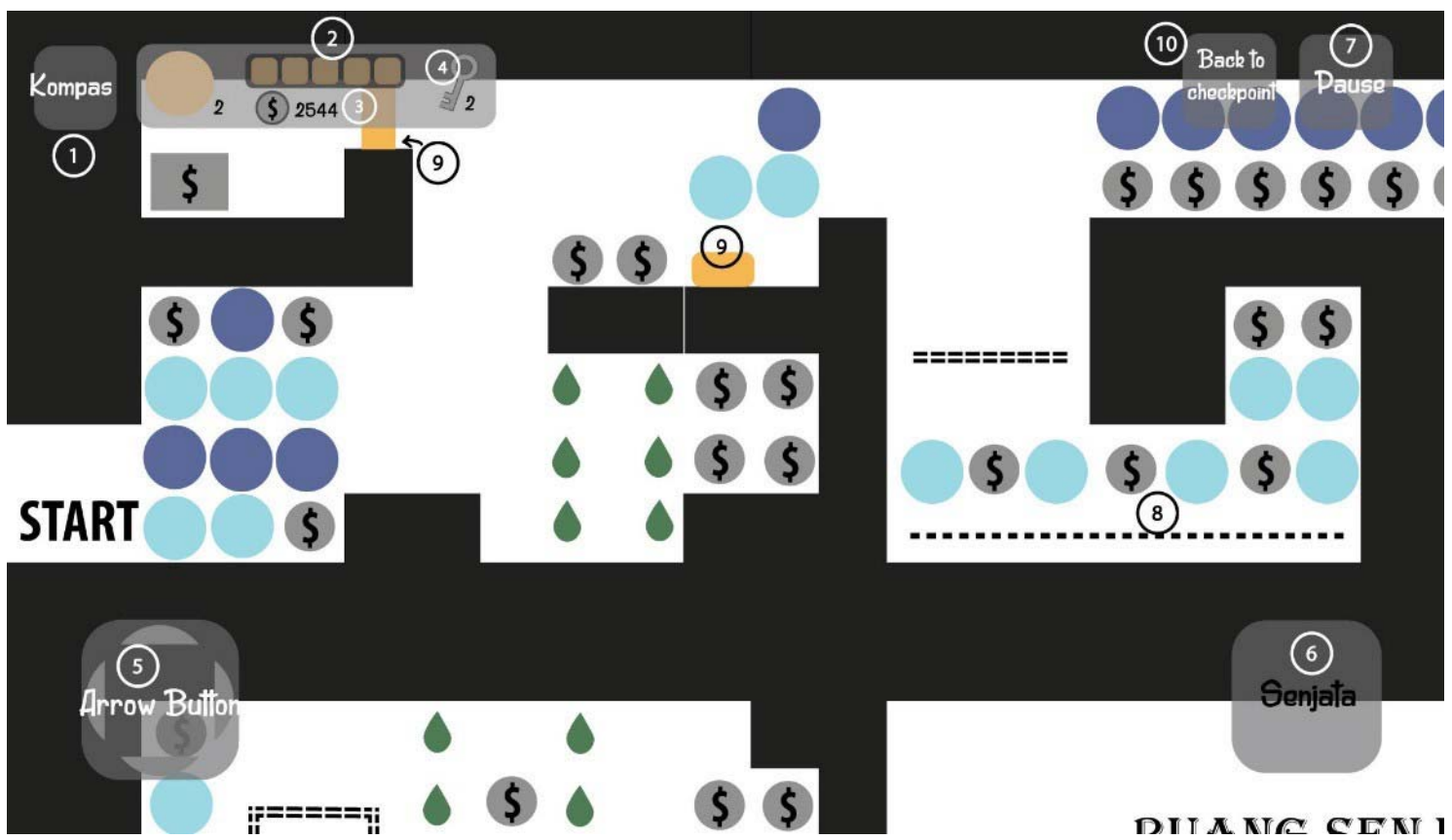

Gambar 3. Desain gameplay

Level dalam game "Lost in Toraja" ditunjukkan dalam pola tiles, yang menyesuaikan dengan kondisi Goa Londa di Tana Toraja.

Dalam gameplay, terdapat indikator-indikator sebagai berikut :

1. Kompas, untuk menunjukkan arah jalan keluar bagi player.

2. Health bar, indikator nyawa player dalam permainan.

3. Indikator koin, menunjukkan jumlah koin yang telah dikumpulkan player dalam level tersebut.

4. Indikator kunci, untuk menunjukkan jumlah kunci yang dikumpulkan player.

5. Arrow button, yaitu tombol yang digunakan player untuk menggerakkan karakter

6. Attack button, digunakan player untuk menyerang.

7. Pause Button, digunakan untuk memberhentikan permainan untuk sementara.

8. Rute musuh, yang berupa garis panjang membentuk rute jalan musuh.

9. Tuas dan pintu. Apabila tuas ditindih dengan batu, sebuah pintu akan membuka ruangan yang dapat diakses pemain. 
10. Back to checkpoint. Tombol ini berfungsi untuk mengembalikan pencapaian pemain ke checkpoint sebelumnya. Pemain dapat memakai tombol ini apabila terjebak.

\section{PERWUJUDAN}

\section{Praproduksi}

Tahap perwujudan praproduksi merupakan perancangan sebuah produk sebelum memasuki proses produksi. Game "Lost in Toraja" telah melalui beberapa tahap praproduksi, yaitu

a. Pengembangan ide yang terinspirasi dari banyaknya budaya Indonesia yang menarik untuk dipelajari. Salah satu budaya yang unik adalah budaya Toraja, yakni budaya ritual kematiannya.

b. Riset mengenai konsep yang telah dipilih, seperti mengumpulkan informasi dari buku, maupun narasumber.

c. Pembuatan concept art supaya hasil akhir visual game selaras dan harmoni.

d. Pembuatan story concept supaya alur cerita sesuai dengan mekanika game.

\section{Produksi}

\section{a. Pembuatan Aset Visual}

Proses aset visual adalah pembuatan objek-objek yang menyusun dan mengisi produk final game “Lost in Toraja”. Proses ini merupakan proses lanjutan dari praproduksi. Pada tahap ini akan dibuat aset visual game, seperti karakter utama, musuh, level tileset, gameplay item, dan UI Button. Komponen-komponen inilah yang akan menunjang visual dari mekanika permainan, sehingga tampak menarik.

\section{b. Pembuatan Cerita Lengkap Permainan}

Sinopsis singkat telah dijabarkan dalam tahap perancangan, namun cerita tersebut hanya merupakan garis besar, dan perlu didetailkan lebih dalam. Berikut ini, telah dijabarkan secara rinci cerita yang akan disampaikan dalam permainan.

Cerita dimulai dengan karakter utama yang bernama Orion, memiliki seorang adik bernama Vega. Suatu malam, Orion bermimpi buruk tentang Vega. Pada saat itu, Vega sedang berwisata di Tana Toraja, namun dalam mimpinya, Vega sedang berada dalam kesulitan. Sudah beberapa hari ini Vega tidak dapat dihubungi. Mimpi tersebut membuat Orion semakin tidak tenang. Ia pun menceritakan mimpinya pada seorang teman yang bernama Nanda. Setelah selesai bercerita, Nanda menyarankan Orion untuk menyusul Vega ke Tana Toraja. 
Berbekal brosur perjalanan yang ada di kamar Vega, Orion berangkat ke Toraja, mengunjungi lokasi-lokasi yang kemungkinan didatangi Vega. Di Toraja, lokasi yang pertama kali dikunjungi Orion adalah Goa Londa. Disana, Orion tak mendapatkan informasi apapun. Ia memutuskan untuk melanjutkan perjalanan ke Desa Kete' Kesu pada keesokan harinya. Saat pulang ke hotel, Nanda mengirim pesan, yang menanyakan keberadaan Orion. Ia membalas bahwa dirinya sedang di Toraja.

Di lokasi kedua, Desa Kete' Kesu, Orion bertemu dengan Pak Suryo, saat sedang berkeliling. Orion menanyakan apakah ada informasi mengenai orang yang hilang di sekitar sini. Sayangnya Pak Suryo merupakan warga baru, dan dia menyarankan agar Orion bertanya kepada Puang Ando, sesepuh di desa ini. Bisa saja Puang Ando mengetahui sesuatu.

Orion menyetujuinya, namun ia harus menunggu karena saat itu Puang Ando sedang tidak di desa dan akan kembali dalam beberapa jam. Sambil menunggu, Pak Suryo menemani Orion berkeliling Desa Kete’ Kesu.

Namun, setelah beberapa jam, Puang Ando tak kunjung tiba. Orion pun ingin melanjutkan perjalanan ke Air Terjun Sarambu. Pak Suryo mempersilahkan.

Sepeninggal Orion, Puang Ando muncul. Pak Suryo segera menceritakan Orion yang sedang mencari saudaranya. Namun begitu nama Vega disebut, Puang Ando tampak teringat sesuatu. Tiga bulan lalu, terjadi sebuah kecelakaan di Air Terjun Sarambu. Seorang wisatawan perempuan meninggal karena terpeleset dan tenggelam. Puang Ando juga mengatakan bahwa pada saat itu ada kakak korban yang berusaha menolong namun gagal. Begitu Pak Suryo menceritakan ciri-ciri Orion, Puang Ando menjadi heran karena atas dasar apa Orion mencari kembali saudaranya yang sudah meninggal.

Pak Suryo yang khawatir, memutuskan untuk menyusul Orion ke Air Terjun Sarambu. Di saat Pak Suryo hendak menyusul, seorang turis, yakni Nanda, rupanya mencuri dengar pembicaraan mereka. Nanda ternyata menyusul Orion ke Toraja. Ia mengkhawatirkan Orion karena pada saat pembicaraan mereka kemarin, Orion tampak tidak mendengarkan dan berhalusinasi. Orion berkata ia ingin mencari Vega, sementara Nanda tahu bahwa Vega sudah tidak ada. Awalnya Nanda tidak terlalu memikirkannya. Namun pesan dari Orion kemarin membuatnya terkejut dan tanpa pikir panjang ia menyusul kawannya ke Toraja. 
Ketiganya menyusul Orion ke Air Terjun Sarambu. Nanda dan Pak Suryo mendapati Orion sedang duduk di sebuah batu tepi air terjun, tampak sedang mengobrol dengan seseorang. Beberapa kali nama Vega terdengar. Saat itulah Nanda mengetahui bahwa Orion mengalami gangguan mental paska kematian Vega.

Nanda menghampiri Orion, dan mengajaknya pulang. Orion terjangkit penyakit skizofrenia, yang membuat dirinya berhalusinasi. Ia menganggap Vega masih hidup dan berusaha menjemputnya.

\section{c. Pembuatan Ilustrasi Cerita Permainan}

Game "Lost in Toraja” memiliki cerita fiksi yang merupakan bagian dari alur permainan. Maka dari itu, diantara level permainan, akan disisipkan cerita yang dikemas dalam bentuk ilustrasi dan narasi. Cerita pada game memiliki 19 ilustrasi cerita, yang sudah meliputi keseluruhan cerita game dari awal sampai akhir.

\section{d. Pembuatan UI Interface}

User interface adalah bentuk tampilan grafis yang menghubungkan sistem operasi dengan pengguna. Tujuan diciptakannya user interface adalah untuk mempermudah pemain mengakses permainan, sehingga pengoperasian permainan dapat berjalan lancar.

UI Interface yang ada pada game "Lost in Toraja” adalah Splash Screen, Main Menu, Journal, Tutorial, Credit, Level Stage, Pause Menu, Win Menu Condition, dan Lose Menu Condition.

\section{e. Implementasi}

Aset visual yang telah diselesaikan kini harus diimplementasikan ke dalam game engine, yaitu Unity. Kumpulan aset disusun sehingga membentuk area permainan.. Rancangan penempatan aset disesuaikan dengan desain level yang telah dibuat sebelumnya. Game "Lost in Toraja" memiliki 9 desain level dengan 3 lokasi yang berbeda, serta 4 chapter cerita.

\section{Pascaproduksi}

Paskaproduksi adalah proses rangkaian akhir dari sebuah produksi. Game "Lost in Toraja” memiliki empat tahap paskaproduksi, yakni :

\section{a. Musik dan SFX}

Musik merupakan elemen yang penting dalam dalam banyak hal. Alunan musik akan menentukan sebuah emosi dan penguatan suasana dalam sebuah 
game, sehingga pemain akan ikut merasakan emosi yang disampaikan. Musik dalam game "Lost in Toraja” menggunakan elemen musik yang tenang namun misterius, disesuaikan dengan genre cerita dalam game.

\section{b. Pengujian Versi Beta}

Beta adalah istilah untuk game yang masih dalam tahap uji coba. Tujuannya adalah untuk menguji dan mencari kelemahan game tersebut, jadi tahap ini adalah tahap perbaikan agar ketika dirilis, game tersebut sudah terbebas dari bug, kerusakan, error, dll.

\section{c. Publishing}

Game "Lost in Toraja" memiliki tujuan untuk menyebarkan budaya Indonesia kepada kancah lokal maupun internasional. Maka dari itu, game "Lost in Toraja” berencana untuk diterbitkan pada website www.itch.io.

Situs itch.io adalah situs di mana game developer indie dapat mengunggah game buatan mereka dan menjualnya dengan metode pembayaran PayPal. Para game developer dapat menentukan sendiri harga minimal yang ditawarkan, termasuk mereka bisa menjual game seharga US\$ 0 .

\section{d. Merchandising}

Karya telah selesai dibuat akan dibuat beberapa merchandise, untuk menambah daya beli konsumen, sekaligus strategi pemasaran yang bagus. Merchandise yang akan dibuat adalah kaos, gantungan kunci pin, mug, mousepad, dan sticker.

\section{PEMBAHASAN ISI GAME}

\section{Prosedur}

Untuk menyelesaikan game "Lost in Toraja", pemain harus mengumpulkan koin sesuai dengan jumlah yang ditentukan pada setiap level. Dalam proses pengambilan koin, pemain harus menghindari musuh dan jebakan, serta menemukan jalan keluar.

\section{Aturan Permainan}

Berikut ini adalah aturan permainan dari game "Lost in Toraja" :

1. Pemain menjadi karakter Orion, yang mencari tahu keberadaan adiknya.

2. Permainan memiliki menu jurnal, yang menampung informasi mengenai Tana Toraja, yang akan didapat selama permainan. 
3. Selama permainan, pemain akan menyaksikan cerita yang dibagi ke dalam 4 bagian, yaitu prolog, chapter 1, chapter 2, dan epilog.

4. Pemain akan melalui 3 lokasi permainan, yakni Goa Londa, Desa Kete' Kesu, dan Air Terjun Sarambu.

5. Masing-masing lokasi memiliki 3 level, sehingga ada total 9 level, yang berupa platform.

6. Pemain harus mencari jalan keluar dari setiap level.

7. Prolog akan muncul setelah pemain menekan tombol "start" pada main menu untuk pertama kalinya. Chapter 1 muncul setelah pemain menyelesaikan seluruh level di Goa Londa. Chapter 2 muncul setelah pemain menyelesaikan seluruh level di Desa Kete'Kesu. Epilog muncul setelah pemain menyelesaikan seluruh level di Air Terjun Sarambu, sekaligus penanda bahwa permainan telah tamat.

8. Karakter dapat bergerak 4 arah, atas, bawah, kanan, dan kiri.

9. Karakter dapat menyerang dengan senjata yang telah diberikan

10. Karakter harus mengambil item "koin" yang tersedia di setiap level.

11. Setiap level memiliki target minimal pengambilan item "koin" untuk memenangkan permainan

12. Terdapat tiga buah peti dalam permainan. Peti warna emas berisi koin, peti warna merah berisi senjata atau kunci, peti warna coklat berisi scroll.

13. Terdapat beberapa checkpoint, tempat bagi pemain untuk menyimpan pencapaiannya dalam level tersebut.

14. Pada awal permainan, pemain diberi 3 nyawa dengan masih-masing nyawa memiliki 5 health bar.

15. Apabila pemain kehilangan 5 health bar, maka dia akan kehilangan satu nyawa. Apabila kehilangan satu nyawa, ia akan kembali ke checkpoint sebelumnya.

16. Apabila pemain sudah kehilangan tiga nyawa, maka pemain akan kalah dan diharuskan mengulang seluruh level dari awal.

17. Karakter harus menghindari musuh dan jebakan. Apabila terkena, akan mengurangi satu health bar. 
18. Karakter musuh adalah zombie, kelelawar, laba-laba, kalajengking, dan lintah.

19. Musuh tidak menyerang pemain, namun memiliki rute gerak tersendiri.

20. Jebakan memiliki pemicu untuk meluncurkan jebakan yang akan menyerang pemain.

21. Jebakan yang tersedia adalah tetesan air asam, topeng toraja, senjata sampit, dan jamur beracun.

22. Musuh dapat dihancurkan apabila pemain menyerang musuh dengan senjata. Namun jebakan tidak dapat dihancurkan.

23. Di setiap lokasi terdapat aset "moveable item", yang dapat didorong pemain, namun dapat menindih pemain hingga mengurangi health bar. Aset tersebut adalah tengkorak, kotak kayu, dan batu.

24. Terdapat pintu serta tuas dalam permainan. Apabila tuas ditindih oleh aset tengkorak, kotak kayu, dan batu, pintu dapat terbuka. Pintu memberikan pemain akses ke sisi lain area permainan.

25. Terdapat aset "destroyable item". Aset ini adalah gumpalan debu, sarang laba-laba, dan rumput. Destroyable item memiliki fungsi untuk menopang moveable items serta koin.

26. Karakter akan mendapatkan item "scroll" yang berisi informasi mengenai Tana Toraja. Informasi ini dapat diakses di menu jurnal, yang terdapat di main menu.

27. Terdapat item kunci, yang memiliki fungsi untuk membuka gerbang. Gerbang memberikan pemain akses ke sisi lain area permainan.

\section{Kendala Produksi}

Proses pembuatan game "Lost in Toraja" tak lepas dari kendala, baik dari proses praproduksi, produksi, dan paskaproduksi. Berikut ini adalah kendala-kendala yang dialami selama proses pembuatan game "Lost in Toraja".

1. Konsep yang mengusung budaya Indonesia

Informasi yang disampaikan dalam game "Lost in Toraja” haruslah akurat dan terpercaya, karena menyangkut budaya Indonesia. Maka dari itu, beberapa 
riset dan wawancara telah dilaksanakan, lalu informasi tersebut disortir menjadi data untuk game ini.

2. Penyesuaian antara budaya dan cerita fiktif

Unsur edukatif yang ada dalam game "Lost in Toraja" agak cukup sulit untuk diselaraskan dengan cerita fiktif yang dibawakan oleh karakter game, yakni Orion.

3. Tingkat kesulitan detail aset visual

Game "Lost in Toraja" memiliki unsur cerita yang digambarkan dalam bentuk ilustrasi. Tingkat detail ilustrasi yang dibutuhkan cukup tinggi, sehingga mengalami kemunduran dari jadwal seharusnya.

\section{KESIMPULAN}

Pembahasan mengenai produk game "Lost in Toraja" telah diuraikan, dan dapat diambil kesimpulan bahwa penciptaan game puzzle berbasis adventure dan story telah selesai dan menghasilkan karya yang cukup sesuai dengan konsep awal, walaupun sempat memasuki beberapa tahap perubahan.

Game "Lost in Toraja" menyediakan banyak fitur yang diharapkan dapat dinikmati oleh pemain, yakni gameplay, cerita edukasi mengenai Toraja, serta cerita fiktif mengenai karakter Orion dalam permainan. Fitur inilah yang menjadi selling-point dalam game “Lost in Toraja”.

Berdasarkan penjabaran diatas, game "Lost in Toraja" merupakan game yang diharapkan akan memberikan kesenangan kepada para pemain, namun turut memberikan edukasi dan wawasan mengenai budaya Indonesia, yakni Tana Toraja, kepada masyarakat lokal maupun mancanegara.

\section{SARAN}

Selama proses produksi Game "Lost in Toraja”, banyak hal dan masalah yang muncul harus dihadapi. Namun, masalah tersebut menjadi pembelajaran bagi game developer dalam pengembangan game selanjutnya. Setelah dilakukan analisa dan observasi selama proses produksi, muncul saran yang dapat digunakan untuk pengembangan gameserupa. Saran-saran tersebut adalah :

1. Mematangkan konsep dari awal, serta melakukan riset mengenai tema yang akan dikembangkan dalam game.

2. Melakukan riset lebih mendalam mengenai tema yang akan dibawa, sehingga akan 
lebih bijak dalam memilih konten yang aman untuk diangkat menjadi game, tanpa menyinggung pihak manapun.

3. Mengurangi mekanisme yang terlalu rumit, khususnya mekanisme "shop" yang merupakan fitur bagi pemain untuk membeli benda-benda yang dapat memudahkan permainan. Mekanisme ini terlalu kompleks untuk digarap dalam waktu yang singkat, walaupun akan menambah daya tarik game dengan cukup signifikan.

4. Melaksanakan proses produksi dengan rencana yang lebih matang dan berencana. Pemilihan pihak yang akan membantu proyek merupakan hal yang vital, karena akan memengaruhi cepat atau lambatnya proses produksi.

Game "Lost in Toraja” masih memiliki banyak kekurangan dalam hasil akhirnya, namun dengan belajar dari pengalaman dan kesalahan yang ada, diharapkan akan menjadi ilmu yang bermanfaat dan menjadi lebih baik untuk kedepannya. 


\section{DAFTAR PUSTAKA}

\section{Buku :}

Dille, Flint, dan John Zuur Platten. 2007. The Ultimate Guide to Video Game Writing and Design. New York: Lone Eagle Publishing Company.

Haryani, Dwi Astuti. 1992. Wisata ke Tana Toraja. Jakarta: Cipta Indah Aksara.

Kalb, Claudia. 1992. Visit Tana Toraja. Jakarta: Gramedia.

Rohan, Hasdianah H. 2016. Mengapa Terjadi Skizofrenia, Pencegahan dan Pengenalan Terapi Gen. Yogyakarta: Deepublish.

Schell, Jesse. 2008. The Art of Game Design : ABook of Lenses. USA: Elsevier Inc.

Tangdilintin, L.T. 1985. Arsitektur dan Ragam Hias Toraja. Ujung Pandang: Yayasan Lepongan Bulan Tana Toraja.

\section{Jurnal :}

Hung, SF. 2016. Schizophrenia. Hongkong: Hospital Authority.

Nooy-Palm, Hetty. 1979. The Sa'dan Toraja. Den Haag: Het Kooninklijk Instituut.

\section{Laman Pustaka :}

https://play.google.com/store/apps/details?id=com.yym.theletter. Diakses pada Rabu, 6 Desember 2017, pukul 13.23 WIB.

https://java.mob.org/game/diamond_rush.html. Diakses pada Rabu, 6 Desember 2017, pukul 13.29 WIB.

http://www.gongstudios.com/mobile-games.html. Diakses pada Rabu, 6 Desember 2018, pukul 14.15 WIB.

https://g2hcombro.wordpress.com/sejarah-perkembangan-game/. Diakses pada

Minggu, 9 Desember 2018, pukul 10.01 WIB.

http://dominique122.blogspot.com/2015/04/pengertian-permainan-games-

menurut-para.html. Diakses pada Minggu, 9 Desember 2018, pukul 10.14 WIB. http://jaribandel.blogspot.com/2015/06/definisi-game-edukasi-menurut-paraahli.html. Diakses pada Minggu, 9 Desember 2018, pukul 11.30 WIB. https://en.wikipedia.org/wiki/Video qame. Diakses pada Minggu, 9 Desember 2018, pukul 11.35 WIB 